\title{
THE BOOSTER-TO-AGS BEAM TRANSFER FAST KICKER MODULATORS ${ }^{1}$
}

\author{
WV. Zhang, J. Bunicei, W.W. Frey, A.V. Soukas, and S.Y. Zhang
}

AGS Department, Brookhaven National Laboratory, Upton, NY 11973

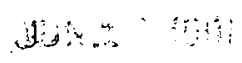

\begin{abstract}
This work describes modulator developments for the Brookhaven Booster extraction and the AGS injection fast kickers. The modulators are projected for both proton and heavy ion operation. The equivalent load inductance is about 2.1 to $2.3 \mu \mathrm{H}$ for each modulator. The PFN voltage is required to be below $40 \mathrm{kV}$ for operation in air. The rise time of the pulse for pro won beam transfer is $120 \pi s$ up to $97 \%$ of full current $(1000 \mathrm{~A})$, and for heavy ion beam transfer, the requirement is $160 \mathrm{~ns}$ up to $98 \%$ of full current $(1615 A)$. During the fourth batch transfer of the proton beam from the Booster to AGS, the pulse fall time of the AGS injection fast kicker has to be very fast ( $<140$ ns), so that it does not appreciably deflect the first batch of injected protons that is circulating in the AGS. To achieve the design specifications, an extensive development effort has been pursued, including distributed parameter estimation and measurement, computer aided analysis and design, pulse shaping and tail-biting circuit test, prota-type construction, etc. The test results will be presented.
\end{abstract}

\section{INTRODUCTION}

The Brookhaven AGS Booster will serve as a multifunction synchrotron injector for the AGS, capable of accelerating protons from $200 \mathrm{Mev}$, the Linac operating energy, to $1.5 \mathrm{Gev}$, at a maximum repetition rate of $7.5 \mathrm{~Hz}$ ( 4 pulses/AGS pulse). The Booster is also capable of accelerating heavy ions to a magnetic rigidity equal to 17.52 Tesla-meters, at $<1 \mathrm{~Hz}$ repetition rate (1 pulse/AGS pulse). Beam transfer from the Booster to the AGS will be bucket to bucket. There are three RF accelerating buckets in the Booster, and twelve in the AGS. During each pulse of proton beam transfer, three Booster proton bunches will be transferred to three of the twelve AGS buckets.

The AGS injection and Booster extraction kickers are the complementary system to each other.

1 Work performed under the ayspices of the U.S. Department of Energy.
Centrally-fed picture frame lumped inductance ferrite magnets are used for both kickers. The kicker parameters are listed in Table 1 and 2. The Booster magnet must be capable of being baked up to temperatures of $250^{\circ} \mathrm{C}$, since the Booster operating vacuum is in the $10^{-11}$ Torr range.

Table 1 - AGS INJECTION KICKER PARAMETERS

\begin{tabular}{|c|c|c|}
\hline & Proton & Heavy lon \\
\hline Rigidity & $7.51 T-m$ & II $T-m$ \\
\hline Strength & 3 mrad & $3 \mathrm{mrad}$ \\
\hline Rise time & $120 \pi s$ (to $97 \%)$ & 160 ns (10 $98 \%)$ \\
\hline Pulse length & $600 \mathrm{rs}$ & $1000 \mathrm{~ns}$ \\
\hline Fall time & $140 \Omega s$ & $<2300$ no \\
\hline Pulse overshoot & $3 \%$ & $2 \%$ \\
\hline Flat top ripple & $<3 \%$ & $<2 \%$ \\
\hline PFN rolcage & $30 \notin V$ & $42 \mathrm{kV}$ \\
\hline Peak current & $1006 \mathrm{~A}$ & $1473 A$ \\
\hline
\end{tabular}

Tatie 2 - BOOSTER EXTRACTION KICKER PARAMIETERS

\begin{tabular}{|l|l|l|}
\hline & Proton & Heavr lon \\
\hline Rigidity & $7.51 \mathrm{~T}-\mathrm{m}$ & $11 \mathrm{~T}-\mathrm{m}$ \\
\hline Strength & $5 \mathrm{mrad}$ & $3.8 \mathrm{mred}$ \\
\hline Rise time & $120 \mathrm{~ms}(\mathrm{to} 97 \%)$ & $160 \mathrm{~ns}(10 \mathrm{9S} \%)$ \\
\hline Pulse length & $>600 \mathrm{~ns}$ & $>1000 \mathrm{~ns}$ \\
\hline Pulse overshoot & $3 \%$ & $2 \%$ \\
\hline Flat top ripple & $<3 \%$ & $<2 \%$ \\
\hline PFN roitage & $30 \mathrm{kV}$ & $40 \mathrm{kV}$ \\
\hline Peak current & $1000 \mathrm{~A}$ & $1615 \mathrm{~A}$ \\
\hline
\end{tabular}

The AGS injection kiciser consists of three lumped magnet sections with equal inductance, which will be driven by three identical pulsers. The Booster extraction kicker has a similar arrangement of four identical subsystems. The load and loop stray inductance is about $2.1 \mu \mathrm{H}$ for each AGS injection subsy-stem and $2.35 \mu \mathrm{H}$ for each Booster extraction subsystem.

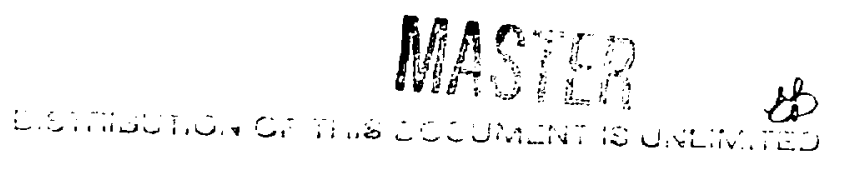




\section{SYSTEM DESCRIPTION}

The modulators are basirally E-type pulse forming networks with equal capacitance and equal inductance for each secrion. The PFN voltage is required to be about $40 \mathrm{HV}$ or below for operation in air. To meet the different kicker curren and rise time requirements of proton and heary ion operation, a terminating resistor is switched to match and mismatch the pulse forming network impedance.

The pulse front edge sharpening is accomplished by using two R-C compensation networks. The $R_{a}-C_{\text {s }}$ in parallel with the first PFN capacitor is an energy compensation network. It provides additional energy needed to build up the current in the load magnet during the later portion of the pulse rise period. The proper selection of $R_{a}-C_{\text {a }}$ will give a fast rising front edge current with an acceptable overshoot or even withoul an overshoot.

A sink netrork $R_{b}-C_{b}$ is used in parallel with the matchirg resistor. The capacitance $C_{b}$ together with the magnet inductance constitute a resonant network that reduces the resistance to the energy discharging of the PFN front edge capacitor during the pulse rising period. The damping resistor $R_{b}$ is used to avoid possible oscillation in the $L-C$ network, and its value should be much smaller than that of the impedance matching resistor. During the lat cop of the pulse, both $C_{a}$ and $C_{b}$ bold at a constane voltage, therefore the pulse flat top is not affected. Figure 1 (a) shows the current waveform of the proto-module of the Booster extraction kicker, and (b) the magnetic field waveform of the proto-magnet. The Booster extraction kicker modulators have been constructed, and are presently in the installation process.

In addition to the fast rise time and low ripple flat top, the pulse fall time of the AGS injection kicker has to be less than $140 \mathrm{~ns}$, for proton injection. A test pulser. based on a circuit improved from a schematic

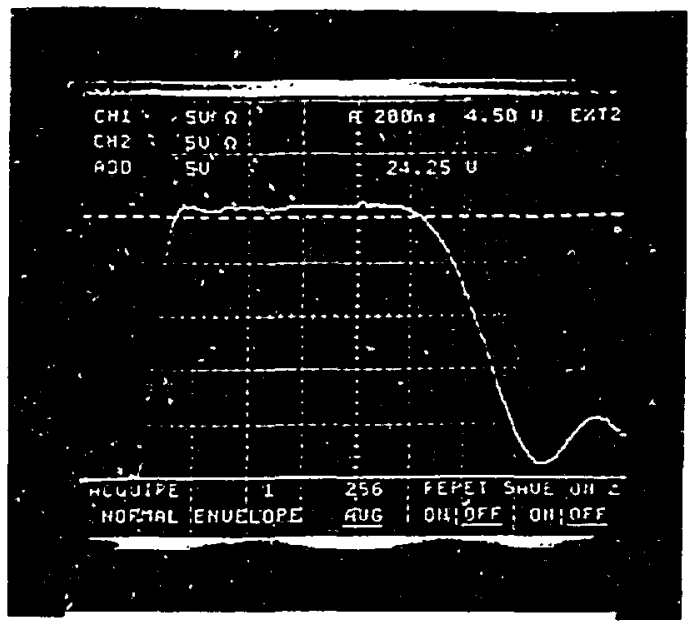

Figure 1 (a). Current pulse waveform.

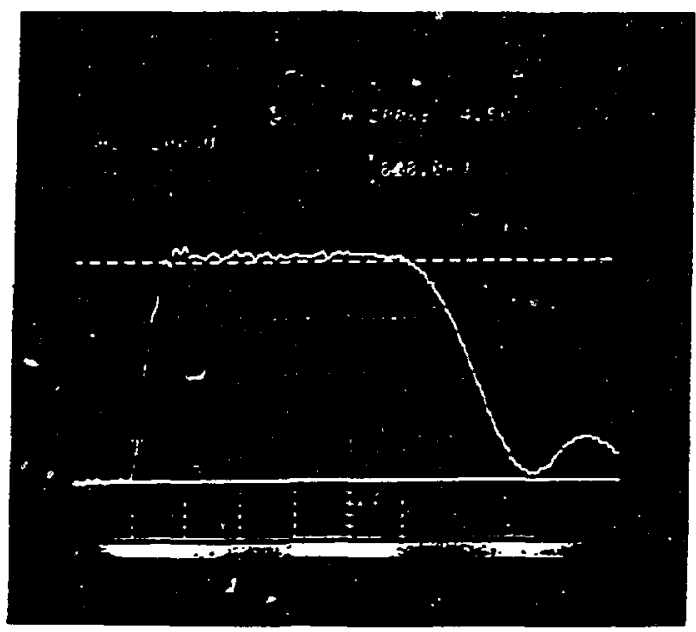

Figure 1 (b). Magnetic field wareform.

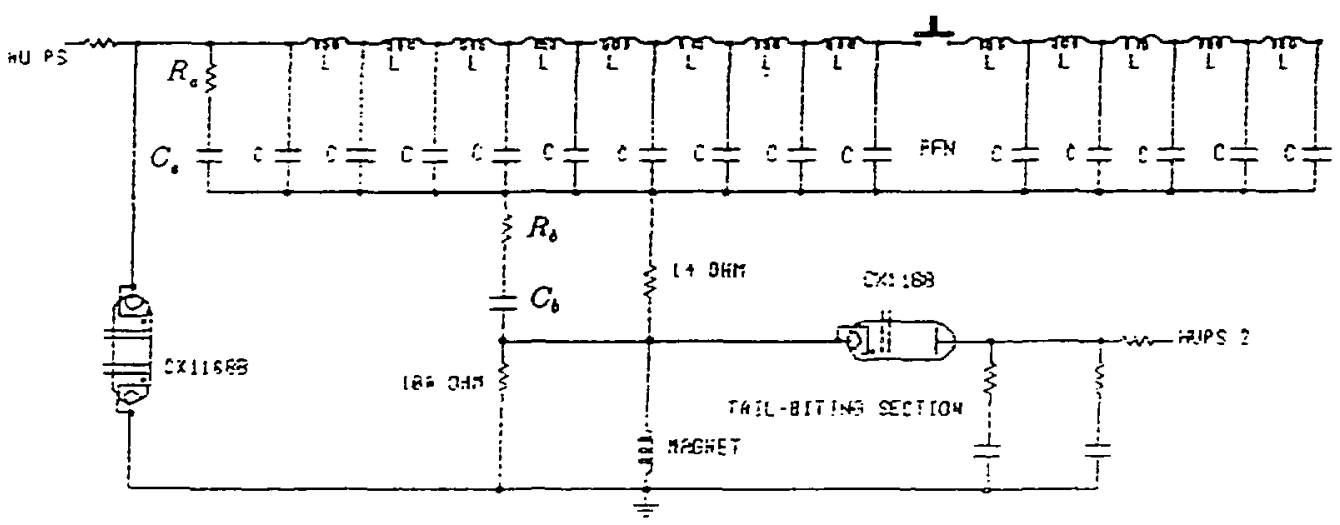


in [2], has been simulated, constructed and tested. The EEV CX-1154 thyrarrons were used as the main switch and tail-bitting switch. This test unit has been powered up to $25 \mathrm{kH}^{\circ}$, and about $900 \mathrm{~A}$ including the tail-bitting function. Figure 2 shows a typical current pulse fall time obtained in this test unit. The construction unit will use two gap thyratrons to increase voltage hold-of capability. Figure 3 is the schematic diagram of the AGS injection fast kicker modulator.

The three modules of the AGS injection fast kicker are being built. Figure 4 shows a curren? waveform from one of the modules with fast fall time. However, the unit was tested only up to $500 \mathrm{~A}$, due to noise problems. Since the modulators vill be mounted inside the AGS ring, limited space makes it rery difficult for package design. The width of each modulator is only 1 foot. The present package design eliminated all thyratron shieldings, which may result in lowering the noise immunity of the floating deck structure of the tail-bitting thyratron. Other factors such as grounding design and trigger scheme may also contribute to the noise problems. Some design changes including an awxiliar trigger circuit of the tail-bitting thyratron, grounding, packaging, and the possible interchange of circuit locations of the main and tailbitting sections are being considered. Testing will resume soon after the Booster installation is complet $=\mathrm{d}$.

Computer aided design and analysis have been used heavily for the modulator development. The pulse distortion due to distributed capacitance and inductance has been investigated by computer simulation and actual test. The test results and simulations have been agreed very well. Some results are included in references [3, 5]. MICRO-CAP $(I, I, I M)$ and $M L T R L X_{X}$ are usti for computer simulation?.

\section{REFERENCES}

[1] "Booster Design Manual," AGS Booster Project, Brookhaven National Laboratory, 1988.

[2] J. Pactsner, Jr.. "A Pulsed Ferrite Inflector for the Emittance Measuring Device of the Chalk River High Current Facility," Proc., 1973 PAC.

[3] W. Zhang, el al.. "Test Fast Kicker Pulser," Proc., 7th IEEE PPC, 1989.

(4) W. Zhang, et al., "Test Modulator of AGS Injection Fast IGicker," IEEE Conf. Rec., 19th PIIS, 1990.

[5] W. Zhang, et al. Report on the Test and Measurement of the Fast Kicker System," AD Booster tech. note \#133. B\L, 1989.

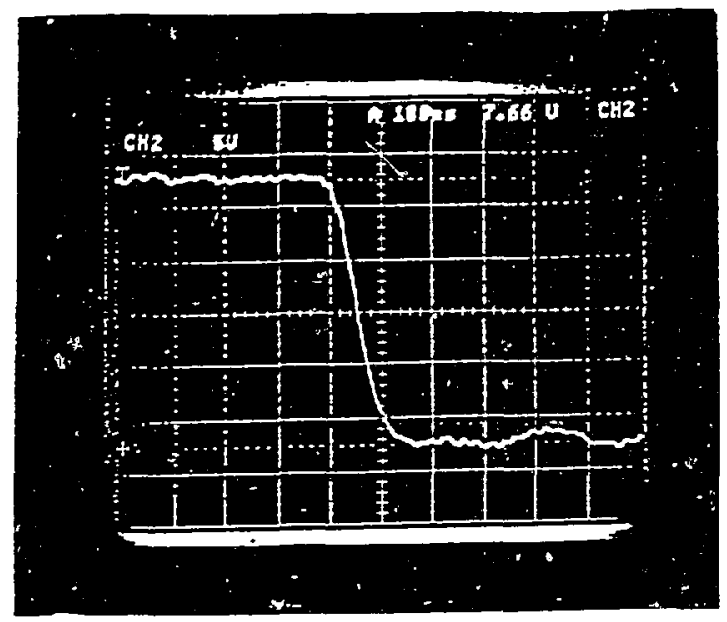

Figure 2 Curreat pulse falling edge with tail-bitciag-

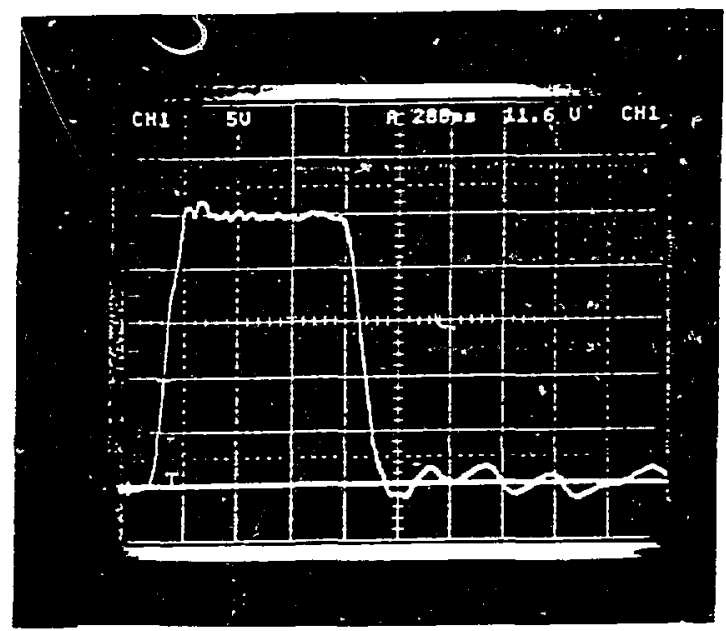

Figure 4. Current pulse wavefora -ith tail-bitting.

2 MICRO-CAP is a profuct of Sprectrum Softwase. Inc. Sunnyvale, $C A$ 94086. $\Lambda L t T R I X_{X}$ is a crademark of Integrated Systems Inc., Sasta Cisra. CA 95054. 